\title{
PICTON/SHUKAKU: Viaje a la Isla de la Memoria ${ }^{1}$
}

\section{PICTON/SHUKAKU: Voyage to the Island of Memory}

\author{
SERGIO MANSILLA TORRES
}

Universidad Austral de Chile

Correo electrónico: sergio.mansilla@uach.cl

\begin{abstract}
En este artículo se indaga en las peculiaridades narrativas de Picton, de Juan Pablo Riveros, libro en principio con características de bitácora de viaje pero que se va armando de un conglomerado heterogéneo de registros textuales, de manera que el relato termina siendo autobiografía, diario, comentarios de textos, historia de una personalidad poética, descripciones de lugar, entre otros aspectos. Se exponen y comentan estas diversas dimensiones a partir de un aserto inicial de base: Picton es la historia de un yo-escritor-memorialista que hizo de los territorios australes su íntima y preciada morada literaria, la que lo nutre de un poderoso compromiso con la literatura, la memoria y los paisajes patagónicos isleńos.
\end{abstract}

Palabras claves: Libro de viaje, memoria, Patagonia, autobiografía intelectual

In this article we explore the narrative peculiarities of Picton, by Juan Pablo Riveros, a book in principle with characteristics of a journey logbook but that sets up a heterogeneous conglomerate of textual registers, so that it ends up being autobiography, diary, textual commentaries, history of a poetic personality, descriptions of places, among other aspects. These diverse dimensions are exposed and discussed initiating from an initial assertion: Picton is the story of an I-Writer-Memorialist who made of the austral territories his intimate and precious literary dwelling, which nourishes him of a powerful compromise with literature, memory, and the patagonian island landscapes.

Key words: Travel Book, memory, Patagonia, intellectual autobiography

\footnotetext{
${ }^{1}$ Este trabajo forma parte de la ejecución del proyecto internacional de investigación Red Temática "Cambio transnacional, desigualdad social, intercambio cultural y manifestaciones estéticas: el ejemplo de Patagonia (2015- 2018)", encabezado por la Friedrich Schiller Universität, Jena, Alemania, con el concurso de las siguientes universidades: Universidad de Chile, Universidad de Concepción, Universidad Católica de Temuco, Universidad Austral de Chile (Chile), Universidad de Buenos Aires, Universidad Nacional del Comahue, Universidad Nacional de la Patagonia San Juan Bosco (Argentina).
} 


\section{Presentación}

Picton/Shukaku (2014) de Juan Pablo Riveros es un volumen de no muchas páginas (78 para ser exactos) pero de una complejidad que sorprende. ${ }^{2}$ Presentado por su autor apenas como una narración que informa de sus estadías infantiles en la isla Picton entre 1947-49 y 1952, evocadas dichas estadías a partir de una tercera permanencia, muy breve esta vez, acontecida en noviembre de 2012, a poco andar, sin embargo, se hace evidente que el volumen es mucho más que esto: asistimos a la narración de una travesía vital por memorias de vivencias australes y lecturas varias las que, a lo largo de los años, han dado paso a la emergencia de un sujeto escritor - Riveros - comprometido con la Patagonia, con sus habitantes (de antes y de ahora), con la historicidad y trascendencia metafísica de estas geografías. Podríamos decir entonces que Picton es la historia de un yo-escritormemorialista que hizo de los territorios australes su íntima y preciada morada literaria, en la que cobran realidad lo que Riveros llama "mis matrices cósmicas” (2014: 36).

Ciertamente el libro aquí comentado puede ser leído como la explicitación de una estrategia narrativa que toma la forma de una historia que relata la conformación de un sujeto-autor-hablante profunda y radicalmente interpelado por (y partícipe de) un poderoso sentido de lugar que se vuelve, en el caso de Riveros, condición de posibilidad de la imaginación poética y de la memoria de lo vivido y lo leído. En esta línea, la ecuación que nos plantea Riveros puede formularse así: el lugar geográfico, en el que se han inscrito huellas de vidas (humanas o no), y las textualidades que representan dicho lugar -representan en el doble sentido de construir una cierta imagen del mismo (de paisaje, por ejemplo) y, a la vez, hablar en nombre de quienes precisamente han dejado huellas en el/del lugar- son instancias que recursivamente se constituyen en un devenir historizado que toma la forma de una narrativa en flujo y reflujo constante entre el ayer y el hoy, entre el yo que evoca un mundo -el de la isla- y ese mismo mundo que ha sido crucial en la conformación de una subjetividad territorializada, patagónica por más señas.

Picton explicita, digamos, ciertas "tecnologías del yo" ${ }^{3}$ que se despliegan en el proceso de hacer memoria. Una de ellas es el establecimiento de un punto geográfico

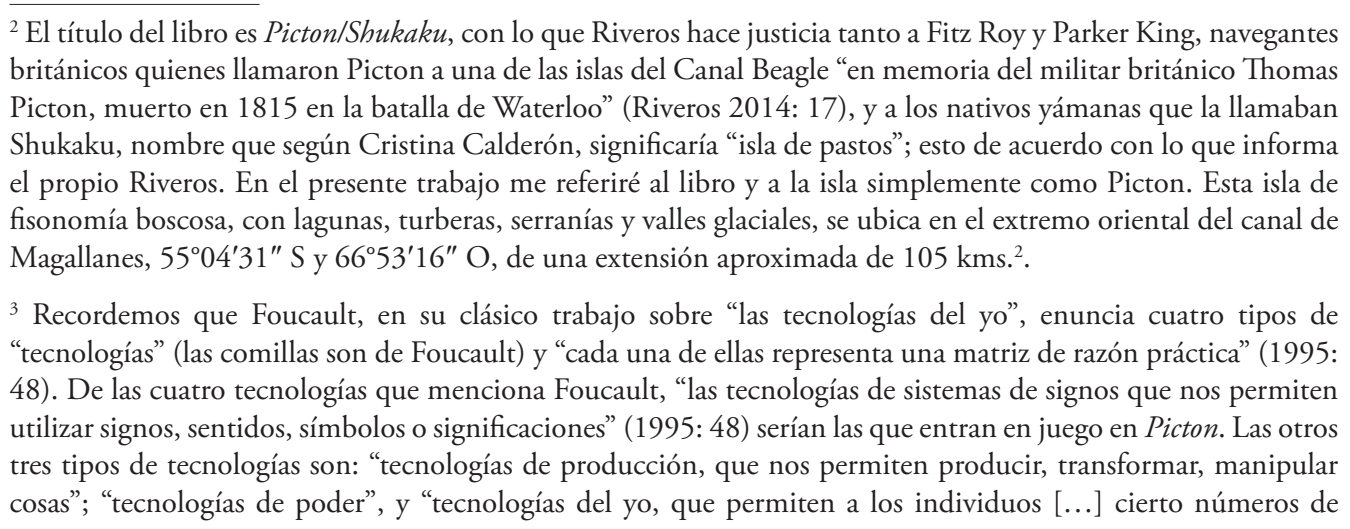


concreto de origen del sí mismo: la isla Picton; a lo que se suma la selección de un conjunto de vivencias acontecidas en la isla que resultaron determinantes para el futuro y que se vuelven, desde el presente de la escritura, material narrativo u objetos de evocaciones más o menos líricas. El proceso narrativo de hacer memoria perfila un cierto devenir discursivo referido a territorios patagónicos, de los cuales Picton es su metónimo; pero las referencias se extienden igualmente a espacios rurales otros portadores de imágenes de plenitud (e. g., espacios evocados en la poesía de Robert Frost). En estas evocaciones se imbrican oralidad y escritura, narración de episodios y descripciones líricas de entornos, miradas hacia el afuera del yo y retornos hacia la intimidad del yo en la que habita un territorio, un paisaje: el yo habitó (y aún habita) en Picton tanto como Picton habita en el yo profundo, en la subjetividad originaria del Riveros escritor memorialista. Digamos, pues, que el libro es el relato de un viaje a (y permanencia en) un lugar en el que la mutua determinación de este doble habitar no ha cesado de acontecer. Relato que se arma a modo de constelación de textualidades que instituyen un lugar simbólico que se monta sobre geografías concretas y que viene a ser -el lugar- la morada fundante y nutricia de la poesía de Juan Pablo Riveros. En este sentido, Picton es al mismo tiempo la exposición de una poética y sus fundamentos. O si se prefiere, la historia de una personalidad poética que, recursivamente, acontece en y gracias al relato mismo que la refiere. ${ }^{4}$

En primerísima instancia, sin embargo, Picton se presenta como el relato de peripecias del viaje que Riveros hiciera a la isla Picton en 2012. Sucede, sí, que en la narración de tales peripecias el autor enmarca relatos que evocan vivencias de su periodo infantil en la isla con otros que evocan sus lecturas de adulto. En este trajín de la memoria se hacen presente, además, relatos de parientes (su padre, por ejemplo) y vecinos alguna vez oídos por Riveros, a los que habría que añadir, claro está, registros y descripciones propias del viaje realizado en 2012. El resultado es un relato de relatos cuyo efecto final viene a ser, por una parte, una densa descripción de la experiencia isleńa de Riveros, vital para su identidad presente; por otra, un recorrido por las lecturas que han instituido su hogar simbólico de escritor, hogar que incluye desde los confines patagónicos hasta lejanas tierras, de otras latitudes, que la poesía o la novela han convertido en poderosas metáforas de lugar (e. g., obras de Hemingway, de Frost). Estamos ante un relato que evidencia los materiales discursivos que Riveros moviliza para configurar una representación esencialmente lírica

\footnotetext{
operaciones sobre su cuerpo o su alma" (1995: 48). Foucault las expone "a modo de contextualización" dado que su interés no es describir cada uno de estos tipos de tecnología en un registro simplemente teórico sino incursionar en la historicidad de tales tecnología.

${ }^{4}$ Con esta formulación sigo de cerca la idea de Paul John Eakin de que autobiografía no puede verse solo como fuente informativa: ella misma es — como lo expone Lorena Amaro al parafrasear a Eakin — "un acontecimiento intencionado que forma parte de la biografía" (2009: 185). Y agrego: si forma parte de la biografía que la autobiografía recoge, entonces la autobiografía será siempre un modo de vivir un determinado tiempo presente —el de la escritura — que requiere ser comprendido y narrado atendiendo a su genealogía y derivas correspondientes. Amaro alude al libro Paul John Eakin En contacto con el mundo: autobiografía y realidad, publicado en Madrid en 1994 por Megazul-Endymion.
} 
y contemplativa de Picton (por encima del formato narrativo del libro): isla-mundo, islahuella, isla-palabra. La memoria viene a ser, entonces, una forma de imaginación poética que exige, sí, ser contrastada con experiencias documentadas in situ, en la isla misma.

Entiéndase el presente trabajo como aproximación a Picton que pretende elucidar algunos de los modos de ser y funcionar de aquellas "tecnologías de la memoria" que Riveros despliega en su relato(s). ${ }^{5}$ No pretendo exhaustividad ni menos ahondar en los problemas teóricos que pudiera suscitar la expresión "tecnologías" aplicadas en este caso a la memoria. Tampoco discutiré la noción misma de memoria (han corridos ríos de tinta sobre el tema), sino solo acudir a ella a modo de noción instrumental que describe una operación textual concreta: la de contar la historia de un viaje que evoca historias de otros muchos viajes, a través de la conjugación de relatos que vienen a describir, desde distintos ángulos y temporalidades, una escena básicamente única. Me refiero a la del poeta que al contemplar Picton contempla, a la vez, el pasado y el futuro, el suyo en primer lugar pero también el de otros que estuvieron/pasaron por Picton y dejaron huella.

\section{Isla Picton Revisitada 60 años después}

"En el reino de la imaginación se es joven muy tarde" (Riveros 2014: 33). La sentencia es de Juan Pablo Riveros y la enuncia al momento de referir y parafrasear la tesis de Gastón Bachelard en lo que concierne al rol que el filósofo francés le atribuye a la poesía a la hora de construir memoria. Bachelard, nos dice Riveros, "apunta que la poesía no nos da tanto la nostalgia de la juventud, lo cual sería pedestre, sino la nostalgia de las expresiones de la juventud... y que con imágenes princeps rumiamos lo primitivo pues en el reino de la imaginación se es joven demasiado tarde" (2014: 33). Semejantes pensamientos son parte del relato del viaje que Riveros hiciera en 2012 a la isla Picton, ubicada en la boca oriental del canal Beagle, en el extremo austral de Chile; viaje que, en realidad, es un retorno a la isla en la que Riveros viviera de niño en dos periodos:

Es una narración, sin duda, incompleta de la estadía con mi familia en isla Picton en los años de 1947/49, y luego, el año 1952. Es, también, la historia de una recuperación y un retorno, después de 60 años.

Mi temprana experiencia en Picton marcó mi manera de ver y entender el mundo. Los ejes centrales son ciertamente mis padres y la isla. Mi padre, el de las aventuras; y mi madre, la de las canciones, lecturas y poemas (Riveros 2014: 9).

\footnotetext{
${ }^{5}$ Ciertamente me apoyo en Foucault al decir "tecnologías de la memoria". Dado que la memoria se manifiesta, en términos discursivos, como relato, no sería impropio concebir los modos de hacer memoria como variantes específicas de los Foucault describe como "tecnologías de sistemas de signos" a las que el yo acude para constituirse como tal.
} 
Riveros acudió entonces a la llamada del niño que él mismo fue y que se quedó en la isla a la espera de que el ahora hombre-poeta retorne a las playas y bosques de Picton -la isla de la memoria- y descifre/evoque las huellas de su propio origen personal y familiar en tanto escritor existencialmente comprometido con lugares y entornos naturales de la Patagonia austral; comprometido, sobre todo, con aquellas memorias escritas y orales de las tierras y aguas patagónicas que Riveros recupera en la forma de tácticas de develamiento discursivo de la profunda humanidad que une al poeta con quienes le precedieron en el habitar patagónico (así no sea un habitar viajero) y en la escritura evocadora de ese habitar/ transcurrir.

Picton, conviene consignarlo, es y no es un libro de viajes; es y no es un libro de memorias familiares; es y no es una autobiografía. Seguro sí es el relato de una poética del retorno; pero de un retorno imposible que incita, por lo mismo, a la despedida y a emprender nuevos trabajos, nuevos viajes, siempre transportando el equipaje de las "imágenes princeps". Es, pues, retorno simbólico al vientre materno -la imagen del nido es recurrente en el libro- tanto como despedida melancólica de su propio pasado isleño; un adiós a ese niño llamado Juan Pablo Riveros quien, con sus padres y hermanos, viviera hace 60 ańos en esa soledades insulares de viento, nieve y temporales formidables, como dice el mismo Riveros. ${ }^{6}$ Ahora, en 2012, Riveros es un poeta que viaja al origen de su propia palabra poética para constatar, no sin melancólica resignación, que la memoria es al mismo tiempo el ser y la nada de lo vivido, o sea, el ser y la nada de su propio lenguajeo literario que se echa al hombro la tarea de trasladar/traducir lo vivido a texto para comprender el presente inmediato como un transcurrir invitante a continuar, mientras quede vida, en la misma tarea de hacer huellas. Si al lenguaje le podemos arrancar palabras evocadoras de experiencias cruciales del acontecimiento de llegar a ser-en-el-mundo -acontecimiento que viene del pasado ciertamente- es porque en el lenguaje se inscriben las huellas de lo vivido. Después de todo, el transcurrir de la vida es, al mismo tiempo, una narración (de la memoria de vivido) sin más desenlace que el de la vida misma. Claro que la memoria comporta también un dolor, una nostalgia: narrar el pasado es un esfuerzo fallido por unificar palabra y realidad. Porque cuando se recuerda, ya no está la realidad que se recuerda, y la memoria dialoga, entonces, con sombras - con las huellas mnémicas- que permanecen bullendo en la retina del presente. Es lo que ocurre en Picton.

Fueron, sin duda, tiempos cruciales. En esa estadía en Picton [la de 1952] se comenzaron a perfilar imperceptiblemente los primeros pilares de toda una vida, los cimientos de mi hogar marítimo y espacial en el cosmos. De cierta manera, casi todos los otros hogares en los que posteriormente ha transcurrido mi vida han sido

\footnotetext{
${ }^{6}$ Riveros nos informa que en 1947-49 compartió con su hermano Jaime, su padres Osvaldo Riveros Saldańa, marinero de la Armada de Chile que realizaba entonces labores militares de soberanía y juridición en Picton, y Domitila Aedo Campos, su madre. En 1952 ya había nacido su hermano Edgardo, quien para entonces tenía un año y medio. Juan Pablo seis y Jaime cinco. En 1947 Juan Pablo contaba con dos años. Más adelante vuelvo sobre la idea de despedida.
} 
posadas o refugios transitorios que pretendieron emular este hogar primero. Desde esa época hasta el presente me ha invadido con frecuencia la nostalgia, un amor especial por esa isla, su silencio y sus paisajes (Riveros 2014: 32).

Hablamos de un libro constituido por registros textuales heterogéneos. En él convergen alusiones y fragmentos de relatos de viaje y de descripciones de los territorios patagónicos realizadas por diversos viajeros y etnógrafos en los siglos XIX y XX, narraciones de episodios autobiográficos referidos principalmente al periodo de infancia isleña de Riveros con su padres, hermanos y amigos de la familia, exquisitas evocaciones de la flora y la fauna de la isla Picton, múltiples referencia a textos literarios -textos de poesía sobre todo- en los que hallamos visiones de plenitud en relación con lo vivido y con lo que resta por vivir. A lo anterior hay que ańadir documentos fotográficos de época (1947-49 y 1952) y actuales (2012) que registran con explícito verismo escenas efectivamente vividas o contempladas en la isla de parte del autor (varias de las fotografías habrán sido tomadas, seguro, del álbum familiar) y que hacen sistema con la pretensión de que Picton se lea como lo que es: un documento de memoria y una "tecnología" para construir un yo que recuerda/viaja al origen.

Picton es, además, una cuidada descripción del entorno natural de la isla; descripción que se apoya en fotografías recientes (de 2012) que muestran escenas de flora y fauna isleńa. En ocasiones Riveros establece contrastes entre el paisaje de la infancia y el paisaje actual registrado en sendas fotografías. Así es como Riveros constata cada tanto que el paisaje que se recuerda a menudo difiere del que efectivamente existió, con lo que da a entender, de paso, que la memoria personal a menudo habla más de los deseos y fijaciones de quien recuerda que de las realidades que son objeto del recuerdo. Como fuere, lo cierto es que el sentido de lugar de Riveros -ahora poeta adulto, nostálgico y contemplativo- aparece mediado por textos filosóficos, poéticos, etnográficos, novelescos, líricos, de variada autoría, de manera que la revisitación del paisaje isleño viene a ser igualmente el momento para revisitar textos de variados géneros que evocan o bien el mismo lugar que evoca Riveros -Picton y por extensión las geografías australes- o bien reproducen la misma o similar actitud de contemplación respetuosa y carińosa de la naturaleza, patagónica o no. En este punto, Riveros no hace distingos entre la mirada europea y nativa, si es que ambas de veras tienen ojos para ver lo que "está ahî": los animales, las plantas, la tierra, el mar; elementos que vienen a ser signos que incitan a la conciencia a un viaje meditativo por la inmensidad del universo. ${ }^{7}$ El libro se presenta igualmente como una especie de informe acerca de la flora y la fauna de Picton que convoca y evoca al Darwin escritor del famoso Diario del viaje

\footnotetext{
7 "Cuando, en noviembre de 2012, arribamos a la playa no había nereidas ni oceánidas, ni se veía a Poseidón con su cohorte y su carro rodeado de delfines. Tampoco estaba Tetis con sus ninfas marinas. Un montón de sueños esperaban a la orilla de la playa antigua. Había, sí, lo principal: un cósmico silencio" (Riveros 2014: 11). El "cósmico silencio" y la consecuente pequeñez humana ante la inmensidad es un motivo recurrente en la poesía de Riveros, y llega a ser central en su Poema del cosmos. Sintomáticamente, al clausurarse Picton, Riveros afirma lo contrario de lo que dice en la página 11: sí habitan las nereidas en las aguas del Beagle, "en las aguas profundas de caleta Banner" (2014: 78).
} 
de un naturalista alrededor del mundo. Con esta estrategia, Riveros recupera, a través de la descripción y evocación de paisajes, las vivencias infantiles y de adulto más significativas, más amadas; aquellas que han sido y son fundamentales para su propia poesía.

Riveros hace suya la tarea formulada por Gabriela Mistral: "entregar a los extraños el paisaje nativo integramente y dignamente" (énfasis mío). ${ }^{8}$ Entregar a los extraños, o sea, a nosotros, a todos quienes no hemos tenido la suerte de pisar, menos de vivenciar, las islas del canal Beagle. Pero aun si las visitáramos, no las veríamos con la integridad y dignidad de quien, como Juan Pablo Riveros, vivió ahí una etapa crucial de su infancia: aquel periodo de la vida personal del poeta en el que, a ojos de Riveros escritor adulto, se forjó el magma primario fundamento de su mundo poético y existencial. Entregar íntegra y dignamente el paisaje equivaldrá, entonces, a mostrar/entregar en la escritura más o menos autobiográfica un paisaje que está lejos de ser solo paisaje: será contemplar paisajes que se metamorfosean en un extendido acontecimiento de memorias discursivas, literarias o no, que arrancan, al unísono, de las imágenes de lugar que Riveros adulto, in situ en la isla en 2012, reconstruye en la mente del niño que fue en 1947-49 ó 1952 y de múltiples textos leídos con posterioridad a los años de infancia y que proveen de claves para "viajar" a los ojos infantiles que ven el pasado en sus detalles reales y simbólicos gracias precisamente a esas lecturas. Las lecturas funcionan, en consecuencia, como vehículos que transportan al sujeto autor-narrador a comprender/textualizar su propio pasado infantil en Picton, aunque el viaje discursivo desborda lo personal: las lecturas son los puntos de fuga por los cuales el paisaje isleño se vuelve convocante de historia, de literatura, de misticismo secular, dando paso a un viaje que nos transporta -a los lectores- a la historia obliterada de los que "murieron de Occidente" y a la promesa de la restitución liberadora de la memoria porque ella sí los arranca de la desaparición. ${ }^{9}$

También se asiste en Picton al acontecimiento de desliteraturizar la literatura en el sentido de arrancar a ésta de una dimensión meramente ficcional, imaginativa, fantasiosa.

\footnotetext{
8 "Nuestra obligación primogénita de escritores es entregar a los extraños el paisaje nativo íntegramente y, además, dignamente". Palabras de Gabriela Mistral que Juan Pablo Riveros reproduce en el epígrafe de su libro. El epígrafe alude al texto "Contar", de 1929, de Gabriela Mistral, y es la oración de cierre de un párrafo referido al paisaje americano. "El paisaje americano es una fuente todavía intacta del bello describir y el bello narrar. Ha comenzado hace unos pocos ańos la tarea Alfonso Reyes con La Visión de Anáhuac, y ese largo trozo de una maestría de laca china en la descripción ha de servir como modelo a cada escritor indoaamericano. Nuestra obligación primogénita de escritores es entregar a los extraños el paisaje nativo íntegramente y, además, dignamente." (en línea).

9 "Murieron de Occidente" es el verso final del libro De la Tierra sin Fuegos, de Riveros. Se refiere a los nativos fueguinos exterminados por los blancos. “¿Dónde está tu pueblo, Temáuquel? / ¿Dónde tus marinos, Watauinewa? / Preguntádselo al Kolliot. / Murieron de Occidente." "Despedida de Martín Gusinde”, 2001: 176). En Picton, Riveros evoca muy de soslayo a los habitantes originarios y no toca el asunto de su exterminio, tema central de De la Tierra sin Fuegos. Sí los evoca, a través de Darwin, como "integrados" a la naturaleza: "En la Tierra del Fuego las mujeres y los niños recogen estas setas [alude a los dihueñes] en grandes cantidades cuando están maduras, y se las comen los indígenas sin cocerlas" (2014: 46). En Picton, la memoria de Riveros instala a los indígenas en un horizonte más personal que histórico, sea por los relatos de navegantes, sea por haber
} 
Riveros, en este punto, opta por una literatura que no vuelve la espalda a las materias del mundo y al trato con ellas en la cotidianidad. La entrada de lo real en la imaginación poética ocurre por varias vías: a través de la evocación documental fuerte de paisajes (al modo mistraliano, por algo el epígrafe), de episodios familiares, de anécdotas cotidianas a partir de hechos vividos con vecinos o visitantes ocasionales en los años en que vivió en Picton, de recurrentes digresiones "ensayísticas" sobre la poesía y la memoria misma. Todo para que al lector le quede claro que cuando se trata de hacer memoria sobre lo vivido, en una isla además perdida en el fin del mundo, la literatura se hace equivalente al ejercicio de documentar (énfasis mío) la fuerza de las emociones y la capacidad de la imaginación poética para crear temporalidad con sentido humano mediante poderosas descripciones de lugar, muy reales, muy íntimas, que dan paso a significaciones reconstituyentes de plenitud ontológica y existencial. Gracias al relato se restituye el hogar primordial, aunque tal restauración no pase de ser un ejercicio de memoria que remacha, al final, la nostalgia por un pasado materialmente irrecuperable.

El libro, por lo mismo, ha de leerse también como incitación a los escritores a que sean fieles a sus locus de origen; mas no para atrincherarse en dudosos provincianismos espaciales o temporales sino para que esos lugares originarios sean lugares de confluencia y tránsito de imaginación, memoria, textualidades varias, espacios y tiempos múltiples, cuyas elusivas huellas se registran en una escritura de experiencias informadas por la palabra literaria y por la evocación (y citación) de textos documentales y disciplinarios (antropológicos, p. e.) que solo cobran sentido realmente significativo -de valor existencial, vital- al ser confrontados con la experiencia de haber vivido ahí (en Picton), de ser de ahí y de ser ahí.

\section{El VIAJE COMO Misión de RESCATE}

El 19 de noviembre de 2012, zarpamos desde Puerto Williams rumbo a isla Picton en la patrullera "Alacalufe", al mando del comandante José Alviña. Disimulé mi ansiedad y sobrecogimiento frente a mis compañeros. Se trataba de una misión de rescate soñada durante 60 años.

Pero ¿̇rescate de qué? ¿Qué quedó rezagado u olvidado en la isla? (Riveros 2014: 13).

En efecto, ¿̇rescate de qué? La respuesta que adelanta el propio Riveros es elusiva en la medida en que toma la forma de un relato que, como se adelantó, se despliega en varios registros que se interconectan, intersectan y, acaso, difractan. La RAE proporciona cinco acepciones al verbo "rescatar", todas las cuales, de un modo u otro, son pertinentes a la hora

conocido algunos de ellos en su infancia en la isla: "Una vez recalaron unos yámanas perdidos. Conversaban con mi padre y los veía hacer gestos indescifrables [...] Los loberos y nativos eran como seres de otro mundo que, acurrucados en su bote, navegaban día y noche por las aguas caudalosas del Beagle"(63). 
de indagar en el horizonte de sentido(s) que se visualiza en Picton:

Del lat. *recaptāre 'recoger'.

1. tr. Recobrar por precio o por fuerza lo que el enemigo ha cogido, y, por ext., cualquier cosa que pasó a mano ajena.

2. tr. Cambiar o trocar oro u otros objetos preciosos por mercancías ordinarias.

3. tr. Liberar de un peligro, daño, trabajo, molestia, opresión, etc.

4. tr. Recobrar el tiempo o la ocasión perdidos.

5. tr. Recuperar para su uso algún objeto que se tenía olvidado, estropeado o perdido (en línea).

Permítaseme comenzar con la proustiana idea del tiempo perdido (acepción 4). Riveros, acompañado de María Álvarez Silva, emprende el viaje a la isla Picton porque fue esa isla en la que transcurrió una parte de su infancia que lo marcó para el resto de su vida. $\mathrm{O}$ sea, en esta dimensión de sentido, Picton es la infancia revisitada. El viaje es, en primera instancia, un desplazamiento físico a un lugar que la memoria de experiencias infantiles —una memoria vaga, borrosa, conscientemente irrecordable quizás ${ }^{10}$ - ha guardado por 60 años, pero es igualmente la concretización de un sueño: volver al lugar que ha sido tan importante en su vida como escritor porque de ese ahí ha provenido gran parte del magma simbólico más esencial que ha servido como material de base para sus libros de poesía. Sin embargo, lo que el poeta halla en Picton es y no es lo que vivió. Lo es en tanto la isla, su geografía y naturaleza, las sensaciones que el paisaje le provoca, lo retrotraen a experiencias vividas en 1947-49 o en 1952 (y recordadas en el ahora). Literalmente, es volver a vivir - pero ahora valiéndose de un poderoso aparato discursivo - lo que en su momento fue vivido en una dimensión más bien sensorial y emotiva; en todo caso, sin la mediación de un sedimentado capital pluridisciplinario de lecturas luego de 60 ańos de vida. Si bien la isla sigue estando ahí, en ella ya no permanece el pasado: no está la casa, no están los padres ni los animales domésticos; en realidad nada de la cotidianidad familiar rememorada hasta el detalle permanece. Contra lo antes dicho, literalmente es imposible volver a vivir ese "tiempo perdido" que tanto importa a Riveros. Perdido, sí, pero también recobrado — sus huellas - a través de una vivencia in situ, en la isla, en 2012.

A primera vista, entonces, Picton, en tanto "diario personal", es la rememoración de los años de infancia en la isla. El viaje de 2012 opera como una instancia verificadora de la memoria infantil, que a veces confirma y otras veces desmiente detalles que Juan Pablo Riveros mantenía en el recuerdo a lo largo de su vida previa a 2012. Viajar a Picton será un modo de recuperar detalles de memoria perdidos o equivocados, estropeados digamos, de manera que la memoria infantil (y de lo infantil) queda corregida, restablecida, restaurada,

\footnotetext{
${ }^{10}$ Tengamos en cuenta que en 1947 Riveros apenas tenía dos ańos. Los recuerdos conscientes de ese periodo, si los hay, serán vagos, extremadamente fragmentarios. Pero la memoria no se reduce a la memoria consciente, menos para un poeta.
} 
por lo menos en parte. Viaje a la memoria personal que es, al mismo tiempo, relato de la propia historia familiar de Riveros en relación con la isla Picton, algo que se hace evidente sobre todo en las fotografías de su familia de origen que acompañan al texto. Por obra de las fotografías, la remembranza adquiere la forma de potentes imágenes documentales de la infancia isleña que retratan (y que vuelven a ser objeto de revisitación) a familiares y amigos hoy ya fallecidos. Es significativo, por ejemplo, el contraste fotográfico que Juan Pablo Riveros establece en la página 76. En la mitad superior una fotografía de 1947 con la siguiente leyenda: "Juan Pablo Riveros y su hermano Jaime, en caleta Banner, 1947". Se aprecia a dos niños pequeños en la playa junto a un cajón de madera, varios tablones amontonados en la playa, al fondo una casa rústica de madera con un corredor elevado a modo de palafito. En la mitad inferior en cambio, una fotografía en colores del mismo lugar tomada más o menos desde el mismo ángulo de la anterior con la leyenda "Playa de Picton, 2012". Se ve solo la playa, el mar, la vegetación al fondo; no se divisa ningún vestigio de casa o de niño, como si la naturaleza hubiera vuelto en gloria y majestad a recuperar su prístino origen.

Semejante contraste es crucial en el relato de Riveros porque es aquí donde se evidencia el ser y la nada de lo vivido:

La casa que habité ya no existe.

Pero me recosté en el lugar en que estaba ubicada hace ańos, como tratando de sublimar o hundir los recuerdos en ese lugar. En una foto guardada del año 47, aparecemos con mi hermano jugando junto a la casa. Atrás se perfilaba el horizonte de bosques de 64 años atrás. Hoy me recosté en ese mismo lugar recreando la situación. Ahora solo está el manchón de lo que fue un lugar. Y hay borrones en mí de lo que fueron mis hogares (Riveros 2014: 77).

Agreguemos entonces una nota distintiva más al relato de Riveros, ya enunciada al pasar en páginas precedentes: Picton es la historia de un relato de retorno tanto como de despedida. Despedida de su propio pasado, no para olvidarlo desde luego, sino para atesorarlo en la memoria como una potencia creadora que renovará la conexión existencial de Riveros con la naturaleza y sus reverberaciones místicas y metafísicas y será — por decirlo de algún modo- la invitación a continuar, con renovadas energías, el compromiso inquebrantable con la palabra constructora de sentido vital en el tiempo que queda antes de la despedida definitiva:

\section{Y me repito con Frost:}

Pero tengo promesas que cumplir, y millas por andar antes del sueño y millas por andar antes del sueño.

El plumaje de las aves se eriza por el viento (Riveros 2014: 78). 
Como sugiere el capítulo último de Picton, titulado precisamente "Las despedidas", rememorar lo vivido y contar lo que se está viviendo a modo de crónica —o sea, narración de lo que ahora se está convirtiendo en pasado- es una manera de tornar en experiencia existencial, con sentido humano, la paradoja heraclitiana de que todo cambia y, a la vez y por ese hecho, lo único que permanece estable en el devenir de las cosas es el cambio. La inestabilidad de las cosas deviene estabilidad de las mismas:

Hoy noviembre de 2012 — merced a la gentileza de la Armada de Chile- he vuelto a la caleta y todo es igual. Pero también todo es porfiada e igualmente distinto. La caleta no es la misma, así como yo no soy el mismo. Nada parece ser siempre lo mismo. Pero todo, al fin y al cabo, es esencialmente lo mismo. La dialéctica entre el azar y la suerte han impreso su rúbrica en ella y en mí. Hubo movimientos de tierra al construir la nueva e imponente casa del Alcalde de Mar actual, trabajos efectuados por el hombre que alteraron levemente el paisaje. Hubo sismos interiores en mi vida. Hubo heridas. Y cicatrices como las del viejo Leviatán en Moby Dick o los restos del pez espada en El viejo y el mar (Riveros 2014: 75).

Todo es "esencialmente lo mismo" porque el mundo material sigue ahí, la vida no ha cesado, las novelas que sirven de punto de comparación están ahí; las crónicas, los diarios de navegación, la poesía de Robert Frost siguen iluminando los caminos existenciales de Riveros. En fin, hay un mundo de materias, de seres y palabras que sigue ahí y que ha hecho posible la existencia de un poeta-cronista llamado Juan Pablo Riveros, mundo que lo sostiene y lo sostendrá mientras quede memoria e imaginación en la persona Riveros. ¿Cómo despedirse entonces de este mundo? Imposible, pero, al mismo tiempo, la despedida es necesaria y ¡̇cómo no, si la vida misma es una despedida permanente? La literatura, más también el recuerdo de la familia, de los amigos, de la isla de hace 60 años o más, proveen de herramientas de significación para hacer sentido sobre el tiempo presente y narrar los retornos y las despedidas propias del vivir, singularizadas esta vez en la infancia en Picton y en el retorno (imposible) a la infancia 60 ańos después en la misma isla. Entonces, en la profundidad del yo, la isla es y no es la misma isla. Picton se vuelve una indagación acerca de la experiencia de revisitar la isla y vivenciar, en consecuencia, el transcurrir de las cosas y las huellas mnémicas que este transcurrir graba en la memoria: es un modo de contemplar el ser y el no ser del mundo y de sí mismo en flujo constante.

El sí mismo de Riveros que este libro construye es el de un sujeto escritor, poeta memorialista y viajero. Eso explica que Picton sea también el relato de un viaje a la cocina literaria de Juan Pablo Riveros. Entiéndase: una excursión a los modelos escriturales que han sido determinantes en sus elecciones de estilo, lenguajes, referentes; determinantes en la conformación de sus estructuras del sentir, para decirlo en terminología de Raymond Williams. "Entonces — dice Riveros- acudía a mi mente un sinnúmero de lecturas y vivencias de Fitz Roy, Darwin, Subercaseaux, Bridges, Gardiner, Gusinde, Emperaire, Coloane" (2014: 14). Tal evocación, variopinta en apariencia, acontece mientras Riveros 
navega en la patrullera "Alacalufe" a la cuadra de caleta Eugenia, preso de la ansiedad, de la nostalgia y la alegría por el próximo arribo a Picton después de 60 años. En este momento del viaje, el relato se vuelve una extensa glosa de los escritos de viaje de Fitz Roy y Darwin, glosa que, sin embargo, habla menos de los viajeros ingleses y más del propio viaje de Riveros (factual y discursivo) informado por estos escritos decimonónicos. Para Riveros, las lecturas de estos escritos han sido en sí mismas experiencias de viajes y memorias que ahora reviven mientras viaja a bordo de la "Alacalufe" contemplando las costas isleñas como si esos relatos de antaño prefiguraran el relato actual de Riveros. Como si la contemplación de la dimensión cósmica de los paisajes que esos relatos de antaño registran reclamara continuidad en la palabra actual de nuestro memorialista.

El relato de Riveros, por lo menos a la hora de narrar el momento de la llegada a Picton, se torna recreación de los relatos de Fitz Roy, Darwin, Stokes en la medida en que la situación circunstancial que vive Riveros — que se halla en viaje por el canal Beagle y oficia de testigo de sus bellezas - es similar a la que vivieron estos viajeros ingleses en el siglo XIX, también en viaje y testigos de la magnificencia del paisaje patagónico de entonces. Juan Pablo Riveros, al glosar estos textos, glosa en realidad el relato de su propia vida de escritor viajero (viajero de palabra y de hecho) valiéndose de las lecturas de Fitz Roy, Darwin y otros.

Un ejemplo que ilustra esta manera de narrar en la que la memoria personal se inscribe en la evocación de crónicas decimonónicas, estableciéndose una interconexión entre el relato de la vida de Riveros y el relato de la constitución histórico-discursiva de la Patagonia, lo hallamos en "Crónicas", sección VIII de Picton. Riveros recuerda que su madre contaba que, cerca de Cabo Cooper, "había pintada una gran piedra con una leyenda en otro idioma apenas legible, restos de una inscripción muy deslavada" (2014: 53). Más adelante nos dice Riveros: "En nuestra visita de noviembre de 2012 logramos identificar la piedra que recordaba mi madre, y que es posible correspondiera a alguna de las que se hayan pintado en la costa de Banner" (2014: 57). Entre estos dos momentos, Riveros introduce un breve relato historiográfico en el que nos informa sobre el viaje de Allen Gardiner, misionero británico, que en 1848 y en 1850 estuvo en la caleta Banner y que luego de haber naufragado (aparentemente a inicios de 1851) pintaron dos rocas en Banner con mensajes que sirvieran a quienes viniesen a rescatarlos dado que se veían en la obligación de dejar el lugar. ${ }^{11}$ De paso Riveros cita a Richard Williams, cirujano de la expedición de Gardiner, cuando se refiere al

${ }^{11}$ Allen Gardiner fue un misionero anglicano. Intentó levantar una misión en Picton en 1850, pero la hostilidad de los nativos y del clima lo obligaron a partir, ya sin alimentos, a Bahía Aguirre, en la Isla Grande de Tierra del Fuego, en la parte que hoy pertenece a Argentina, en marzo de 1851. Dejó señales pintadas piedras en caleta Banner (Picton) justamente para quienes vengan a rescatarlos sepan dónde hallar a él y a sus compañeros. Se estima que falleció de hambre y de enfermedades el 6 de septiembre de 1851; llevó un diario hasta último momento. Sus escritos y los del cirujano Williams, según consigna Riveros, fueron recuperados por el comandante de la nave "Dido" que el 22 de enero de 1852 halló los cadáveres de Gardiner y sus compañeros en Puerto de Los Españoles, Tierra del Fuego. Riveros cita pasajes de estos diarios, tomados de fuentes inglesas en línea mencionadas por Riveros (cf. 54 y 55); los pasajes citados están traducido por el propio Riveros. En la sección "Crónicas" igualmente cita bastante in extenso a Anne Chapman quien aporta más antecedentes sobre la muerte de Gardiner y sus hombres. 
paisaje y clima de Tierra del Fuego en lo que Riveros describe como "la primera impresión sobre Fueguia, aplicable a la Isla Picton en ese diciembre de 1850" (2014: 54, énfasis mío). “Es una tierra de tinieblas, un escenario de salvaje desolación; ambos, paraje y clima, concuerdan en carácter, el uno es tosco y desolado, el otro tempestuoso y negro" (Williams, citado por Riveros 2014: 54). Remarco "aplicable" porque evidencia el hecho de que Riveros ve Picton no solo con ojos del niño que fue sino también con los ojos de quienes escribieron crónicas muchos antes que él, de manera que la crónica de 2012 es, en cierto modo, una continuidad de la misma gran crónica colectiva que tantos han venido escribiendo desde hace mucho sobre estos lugares dotados de un paisaje y un clima que liga al humano con una dimensión metafísica de los paisajes. Contemplar los paisajes patagónicos es, de hecho, tener una visión en que lo místico, lo metafísico y lo poético se tornan indistinguibles.

Tal intertextualidad con los libros de viaje no queda circunscrita a la sola narración de la historia personal de Juan Pablo Riveros. Al contrario, el efecto de densificación escritural viene de al menos cuatro causas que se intersectan; digamos, serían cuatro "rescates" que ocurren en y gracias a la escritura de Picton:

1. Del propósito de Riveros de narrar/ recrear/ rescatar su permanencia en Picton cuando niño emana un relato autobiográfico parcial — "es una narración, sin duda, incompleta" (2014: 9)— que se apoya, además, en anotaciones de un diario personal del autor de 1983-84 y del registro cronístico de su viaje de retorno en 2012. Los años de 194749, 1952, 1983-84, 2012 se pueden ver, entonces, como momentos singulares de la vida de la persona Riveros pero que denotan la continuidad del habitar en la isla de la memoria. Si el tiempo físico es irreversible, el de la memoria — para decirlo de un modo figurado- es cuánticamente reversible. En este escenario, el relato autobiográfico toma la forma de una propensión sostenida a desplazarse hacia el origen de su condición de escritor-lector de textos y geografías australes, origen incluso anterior al lenguaje, anterior al yo.

2. De los escritos de exploradores extranjeros, especialmente británicos, del siglo XIX, en los que los autores consignaban observaciones de lo que veían o experimentaban, hechas todas con "ojos imperiales" pero no exentas de sensibilidad lírica ante la inmensidad y belleza del paisaje, Riveros extrae una potencia descriptiva y simbólica de la que se apropia. Se siente deudor de ese lirismo y paga la deuda —o sea, el rescate—haciéndolos fragmentaria y selectivamente suyos, con lo que viene a reconocer en ellos a los fundadores discursivos de la Patagonia moderna.

3. Riveros debe también mucho a la literatura de ficción en la medida en que es ella la que lo provee de medios imaginativos que terminan densificando sus evocaciones de lugar. Las recurrentes alusiones a textos narrativos y líricos operan como instancias de producción de una simbólica poderosa en el sentido de perfilar un horizonte existencial comprometido con las materia físicas de la Patagonia (paisajes, flora, fauna) y con los destinos humanos vinculados con ese entorno, destinos que Riveros intuye conectados a una metafísica del cosmos.

4. Rescate de la memoria histórica. En el horizonte político de la narración está la memoria de una historia de tragedias y exterminios de la que los habitantes nativos de las tierras magallánicas fueron víctimas de parte de empresarios, aventureros y asesinos 
occidentales. Los mismos que incorporaron la Patagonia a la nación chilena o argentina, según sea, en el marco de la expansión global-colonial de capitalismo decimonónico consustancial a la formación más o menos definitiva de los estados nacionales a la vuelta de 1900. Dado este hecho, el viaje al origen no es solo un retorno a un tiempo anterior al lenguaje. Picton, la isla, con su magnificencia silvestre, es un asomo poético-experiencial a los tiempos anteriores a la modernidad. ${ }^{12}$

La confluencia de estos campos discursivos con sus respectivos ámbitos de referencia viene a ser la estrategia textual que le permite al autor-narrador erigirse como un sujeto viajero que toma la posta en la carrera de continuar con el trabajo de la fundación discursiva de los territorios patagónicos. Desde los tiempos de Darwin y Fitz Roy han transcurrido poco más de 150 años (y eso, sin contar los escritos de Francisco Cortés de Hojea sobre el descubrimiento del Estrecho de Magallanes por parte del capitán Juan Ladrillero en 153738), y en ese periodo se han acumulado sedimentos de historicidad y de discursos que han dado forma a paisajes simbólicos e históricos que no se pueden simplemente ignorar: tierras ignotas, de agrestes soledades y vientos rudos, hielos, pampas, mares, islas deshabitadas o apenas habitadas por seres situados en las fronteras del mundo (de Occidente) son atributos patagónicos que endilgan la mirada hacia una comunión entre lo humano y el cosmos en un tiempo que se difracta del de la modernidad occidental.

Cronista tardío, Riveros no fue testigo directo, presencial, de la violenta y despiadada irrupción de la modernidad decimonónica agenciada por una clase empresarial sin escrúpulos y por un estado nación que, en su momento, convenientemente la amparó. De lo que sí puede dar fe es de su íntima relación con Picton, con su familia de origen y amigos de entonces y de las lecturas posteriores que han sido cruciales para construir una memoria que se extiende a un tiempo anterior a la memoria personal de Picton. Hablo de un ahora en el que se despliega una crítica política a la fundación de la Patagonia moderna tanto como una nostalgia por un mundo perdido, anterior a la colonización occidental, cuya expresión residual de ese mundo fueron, en el caso de Riveros precisamente, las vivencias infantiles en Picton. Recordar/ recrear/ recuperar discursivamente la infancia es entrever lo que fue ese mundo patagónico anterior a la historia occidental; mundo que adquiere contornos más precisos justamente por las lecturas de los textos de aquellos cronistas viajeros que lo vieron por primera vez y dieron cuentas de esas visiones en sus diarios y bitácoras.

Nuestro autor, en consecuencia, se construye como un sujeto narrador que no puede referirse a Picton ni al devenir vital que deriva del hecho de haber vivido en la isla y volver a ella en 2012 sino a partir de y mediante escritos previos, los suyos incluidos (su diario, su propia poesía), que in-forman su relato y lo instalan en la escena de la aludida

\footnotetext{
${ }^{12}$ Como ya se indicó en una nota anterior, Riveros toca este punto de un modo indirecto, indicial. Al respecto, es significativo que Riveros rescate la figura de Benjamín Subercaseaux y su novela Jemmy Button, de 1949, una de las lecturas fundantes del mundo literario y existencial de Riveros. Cuando alude a cronistas europeos de la Patagonia, Darwin incluido, enfatiza la dimensión lírica, sensible, de sus escritos, es decir, lo no imperial de su mirada.
} 
carrera de posta por la fundación/ conformación discursivo-identitaria de la Patagonia profunda. ${ }^{13}$ Riveros es un cronista "tardío" en la medida en que los discursos cronísticos originarios y fundacionales de la Patagonia moderna ya existen: están ahí modelando e informando, para bien o para mal, la representación de los territorios fueguinos. Riveros no se sustrae a ellos; al contrario, los incorpora al relato de episodios de su propia vida, porque al examinar su vida de escritor, con la memoria de un hombre de 60 años o más, no puede sino reconocer que esta nunca hubiera sido lo que efectivamente ha sido y llegado a ser sin ese caudal de vivencias patagónicas en las geografías australes y sin el vasto conglomerado de lecturas alusivas a esas geografías y a los destinos humanos que en ellas o por ellas se dibujan.

Historia de un rescate, entonces, que toma la forma de un relato que se arma a través de una decantada selectividad discursiva, que no distingue entre voces nativas o extranjeras, al servicio de dar cuenta de un origen que ha sido determinante para las elecciones poéticas y existenciales de Juan Pablo Riveros. El viaje a Picton en 2012 habría, pues, que interpretarlo como una instancia de acercamiento íntimo y necesario a las materias patagónicas (léase paisajes, flora y fauna, gente); íntimo por la proximidad sensorial y emocional que implica el estar-ahí de nuevo después de tantos ańos, necesario porque Riveros se impone la tarea de reconstruir y recuperar la memoria infantil — de paso homenajear a sus padres - $y$, al hacerlo, confirma que hay una poderosa materialidad fundante de su propia literatura: la realidad natural-histórica-personal-discursiva de la Patagonia, el verdadero lugar literario y existencial de Riveros.

Sabemos del viaje de Riveros de 2012 por lo que él mismo relata: "un relato eminentemente marítimo desde una isla del sur de Chile" (Riveros 2014: 9). Y ese relato deviene acta que registra el rescate de una vida más interior que exterior ("la lentitud de los pausados procesos interiores", dirá el autor) poderosamente modelada por las memorias australes, marítimas, isleñas, profundamente conectadas con la naturaleza patagónica. "En realidad, comencé a navegar antes de nacer. Ya en enero de 1945, navegué con mis padres en el buque mercante 'Villarrica' desde Talcahuano a Punta Arenas. Ese hito marca el inicio de esta historia" (Riveros 2014: 9). Inicio de la historia personal-biográfica, habría que aclarar, porque si atendemos al devenir del misterio del cosmos y su silencio (o su música, según se mire) - misterio tan caro a Riveros por lo demás - la historia de este devenir, que también se relata en Picton, no tiene ni inicio ni final, o, si se prefiere, lo que se experimenta como comienzo y final son apenas instantes que delimitan la vida de un hombre, insignificantes ante la grandiosidad del cosmos. El libro se vuelve entonces rescate-relato de esta visión metafísica tan determinante en el sistema poético de Riveros. A modo de ejemplo y a propósito de la grandiosa presencia del mar en la isla, Riveros es muy gráfico:

\footnotetext{
${ }^{13}$ El concepto de "in-formación" viene del campo de la física teórica; alude a la idea de que universo no solo es materia y energía sino sobre todo es información, esto al modo de la información contenida en los genes de los seres vivos que hacen posible la existencia de sujetos concretos con determinadas características, o sea, le dan una forma concreta al tiempo que dicho sujeto sigue siendo fuente de información de eventuales nuevos sujetos. Ver al respecto el Universo in-formado de Ervin Lazlo.
} 
Dice Gabriela Mistral en su Poema de Chile:

¡Quedaremos dormitando

oyendo al Gran Loco Suelto,...!

("El mar")

Como señala Otto ${ }^{14}$, supe intuitivamente del misterio de lo sacro, y del mysterium tremendum, al experimentar el espacio terrible en que se manifiesta el enigma de lo inefable y numinoso. De aquello tremendo que, como una fuerza formidable y pavorosa, se manifiesta esplendoroso en el silencio. Y, sin duda, lo que abundaba en Picton era precisamente el silencio, en acorde con la monodia perfecta del mar (Riveros 2014: 41).

\section{LAS HUELLAS DE SÍ MISMO EN LA ISLA}

¿Es Juan Pablo Riveros quien realmente habla en Picton? ¿Este señor que se exhibe estudios doctorales en economía en la Universidad de Lleida y que, según se consigna en la solapa 1 del volumen, ha escrito y publicado varios libros de poesía, todos temáticamente vinculados con los territorios patagónicos y antárticos? Definitivamente sí, a condición de que entendamos que el Juan Pablo Riveros, viajero-cronista-sujeto narrativo y lírico, protagonista de su propio relato, corresponde a aquella dimensión de la persona Riveros que se instituye y constituye como voz de memoria evocadora de un devenir vital esencialmente patagónico por un lado y esencialmente poético por otro. En este devenir, un cierto universo de escrituras ficcionales y documentales que tratan de viajes y lugares y de los efectos metafísicos de estos escrituras que, como se ha dicho, aparecen aludidas o citadas en Picton - ha sido determinante para la conformación de su identidad de escritor en viaje; pero también lo han sido episodios y experiencias vividos en sus años infantiles (y que vive/ rememora de nuevo en 2012) en Picton con su familia, con sus animales domésticos, con la flora y la fauna de antaño y de ahora. Es que ambas dimensiones son dos caras de una misma moneda: vivir en relación con las cosas del mundo y vivir en relación con las palabras que nombran estas cosas y las retienen son aspectos constitutivos de un mismo y extendido acontecimiento: el incesante viaje hacia el origen discursivo e histórico del territorio Patagónico es al mismo tiempo un viaje hacia el origen de su propia palabra literaria comprometida con ese cronotopos-mundo llamado Picton.

Claro que el Juan Pablo Riveros que habla en el texto no es sino aquel que se configura en el acto mismo de narrar(se) en los términos ya anotados más arriba, vale decir, una voz-sujeto-viajero hecha de retazos de crónicas, de libros de viajes y etnográficos, de novelas, de poemas, entre otros, que se articulan a modo de collage fluctuante entre géneros textuales (si bien, lo narrativo prevalece al menos en lo formal); también de imágenes de infancia en Picton, de remembranza de episodios del viaje de 2012, de una actitud de respeto y carińo por la naturaleza patagónica. Porque es una naturaleza que lo transporta

\footnotetext{
${ }^{14}$ Se refiere a Rudolf Otto.
} 
al origen de su propia habla, o sea, al origen de sí mismo, de su existir en tanto Juan Pablo Riveros poeta-cronista-viajero-lector de textos y de geografías australes. Es por los senderos de esa naturaleza rizomática y a la vez territorializada, igual y a la vez diferente a la de su infancia, donde deambulan los espectros de los indígenas exterminados por los agentes asesinos en nombre del progreso y la modernidad expansiva de la nación chilena a la vuelta del siglo XX, y es en ella, en esa naturaleza, donde Riveros encuentra asiento físico real para situar sus memorias de escritor-lector patagónico.

El discurso de la memoria toma en cuenta hechos esenciales que garantizan que el relato está ahí para transportarnos a temporalidades y espacialidades de un ayer que interpela urgentemente al presente. Escribir un libro entero sobre una minúscula isla en la desembocadura oriental del Canal Beagle, con escasos habitantes humanos, evocando una infancia que transcurrió con la normalidad habitual de la de cualquier familia isleńa instalada en las lejanías del mundo, puede parecer un gesto rutinario que da paso a una narrativa que trae a la memoria una historia en la que, en apariencia, nada épico sucede. Es que de esto precisamente se trata: Picton es el lugar físico, en el que Riveros tuvo la suerte de vivir en momentos cruciales de su vida, en el que la memoria evocativa supera lo que Pound llamó el "provincianismo temporal", tan condenable, según el mismo Pound, como el "provincianismo espacial". La tarea del poeta-memorialista sería entonces "comprometerse en un ataque contra el provincianismo temporal... Su trabajo consiste mucho más en desenterrar las cosas valiosas olvidadas que escribir grandes volúmenes 'acerca' de aquello o lo otro" (Pound, citado por Claro 2012: 691). Es con esta "excavación" que se crean las condiciones narrativas para traspasar límites de épocas y entrar en contacto íntimo con el pasado revisitado y revivido en la palabra-imagen y gracias a ella. Tal intimidad con el pasado permite sentirlo actuando (no se trata solo pensarlo o de recordarlo sin más) en el aquí y ahora de la escritura y la vida como una poderosa escenificación que nos expone a las soterradas huellas de la barbarie de una historia de intolerancia y desprecio por el no occidental inscritas en la solemne y magnífica naturaleza isleña, la misma que con palabras mudas habla por quienes alguna vez fueron sus huéspedes humanos originarios.

La naturaleza sigue ahí, poderosa, fiel a sí misma; a su manera es una perseverante testigo de cargo contra quienes vieron en ella solo un botín por el cual se podía matar o morir sin contemplaciones. Es Juan Pablo Riveros, el poeta, el viajero, el cronista (también el economista ¿por qué no?), quien nos hace ver en la Isla Picton no solo una isla, no solo un paisaje: Picton es el punto de feliz confluencia de varias realidades que, a modo de legos, se ensamblan para formar un mundo a la vez literario y experiencial. La infancia de Riveros (y la memoria de ésta); el retorno al país natal del ser-en-el-mundo; la memoria de lecturas de textos de exploradores, literatos y etnógrafos que han contribuido decisivamente a fundar el imaginario patagónico en occidente, mas también relación de lecturas de textos ficcionales que han puesto al desnudo la barbarie y obsesiones destructivas de la modernidad blanca en las periferias de occidente (e. g. la novela Jemmy Button, de Benjamín Subercaseaux; Moby Dick, de Herman Melville; El viejo y el mar, de Ernest Hemingway); la bella y sublime persistencia de la naturaleza que, como sugerimos, no ceja de hablar por los muertos: 
todo ello junto convierte a Picton en un lugar-mundo. Entiéndase: un lugar en el que las materias, los símbolos, el adentro y el afuera de las cosas y las personas; el antes, el después, el ahora del tiempo histórico y personal, acontecen como una trama interconectada lo suficientemente productiva en términos de significaciones como para sustentar una poética personal y una poiesis colectiva. Uno de los aspectos más seminales de Picton es que siendo un texto de textos es, en simultáneo, un relato que nos instala en la realidad material de la vivencia isleña de Riveros, en los viajes patagónicos antiguos y actuales y, además, nos hace ver el proceso experiencial de gestación de este mismo relato así como de la serie poética, la de Riveros, de la cual el libro Picton forma parte.

Picton, la isla, y Picton, el relato, son huellas de un mundo perdido que, no obstante, existe y seguirá existiendo como huella de la misteriosa vastedad del tiempo y del espacio:

¡Huellas! Palabra mágica que, como las cucharadas de té de Proust, me evocaba un sinfín de imágenes fantasmagóricas. ¡Las huellas de la isla! Pero ¿qué era, es una huella? Reverberaciones metafísicas brillaban tras esa palabra simple... huella, pisadas, senderos hollados en el misterio de los bosques... pisadas estampadas - ¿Por quién? ¿De dónde? ¿Hacia dónde?-. Alguien iba o venía. Huella, con su sonido enigmático, resonaba en mí como la palabra trinche, un mueble de comedor con vitrina que usaba mi madre. Una simple huella que dejan los hombres y las huellas que dejan los baguales o los zorros en el bosque encantado de Picton, como un acorde del mar y de los coihues. La huella de los pájaros. La huella del hombre en el cosmos, en estrellas o planetas ignotos. $Y$ dije antes que alguien iba o se dirigía, en lugar de encaminaba, pues esto presupone un camino, y ésta es una palabra demasiado grande y distinta, demasiado civilizada ante una simple y rústica o salvaje huella. Las huellas presuponen un territorio salvaje o intransitado. Las pisadas en terrenos hollados, como los clichés, no dejan huella (Riveros 2014: 39-40).

La cuestión de la "huella", tal como la entiende y la trata Riveros en su libro, daría por sí sola para un artículo completo. Baste por el momento anotar que Picton, la isla, puede verse como un territorio salvaje e intransitado —o transitado por seres que están al margen del devenir pedestre, masivo e indiferenciado de nuestra civilización moderna, urbana-, que retiene las huellas de un mundo perdido que solo la memoria y la imaginación pueden, en parte, recuperar; es más, la isla misma es huella geológica, cósmica, que trae reverberaciones de épocas que nos transportan a los primeros días de la creación del mundo tanto como a los primeros días de la creación poética: la infancia del cosmos es a la infancia del poeta y viceversa. Y anotar que Picton, el relato, es el desciframiento — provisional, aproximativo, imaginativo, como lo es la literatura cuando se echa al hombro el mundo de la vida - que toma la forma de un "retorno al país natal" que es, sin embargo, el retorno a la casa que ya no existe.

Un retorno al hogar que solo está en el pasado y en el futuro pero nunca en el presente. "No hay Presente, decía Pound, — hay Pasado y Futuro y hay Arte" (citado por 
Claro 2012: 692). Arte de construir el único lugar posible que un poeta sabe de veras habitar: el de la Palabra que desplaza la experiencia vivida a la condición de viaje por las texturas interrelacionadas del tiempo histórico, cósmico, psíquico, y del espacio geográfico, metafísico, cósmico y también psíquico (porque en la psiquis tiempo y espacio se unifican). Hay Arte en Picton ¡cómo no! "Y millas por andar antes del sueño / y millas por andar antes del sueño": he ahí el futuro del pasado, de su pasado, que Riveros latamente evoca. Futuro que Riveros se está construyendo ahora mismo de la mano de Robert Frost, al escribir él mismo y al citar sus versos. La poesía deja huellas por donde pasa y tales huellas ayudan a la vida a desplazarse por terrenos no hollados: señales de ruta que conducen al navegante viajero a la isla imposible de la infancia. La isla, la casa que ya no existe, el viaje mismo, son igualmente huellas de una realidad mayor: el cosmos en su plenitud inalcanzable pero siempre invitante a continuar. La poesía es (la expresión de) esa continuidad, poesía que interpreta y sigue entonces las huellas que ha dejado la vida inscritas en la memoria. Mas también se trata de las huellas que la memoria no cesa de inscribir en el relato de una vida en trayecto, la de un sujeto siempre despidiéndose, siempre retornando.

\section{Obras Citadas}

Amaro, Lorena. Vida y escritura. Teoría y práctica de la autobiografía. Santiago de Chile: Universidad Católica, 2009.

Claro, Andrés. Las vasijas quebradas. Cuatro variaciones sobre la 'tarea del traductor'. Santiago: Ediciones Universidad Diego Portales, 2012.

Cortés de Hojea, Francisco: "Viaje del capitán Juan Ladrillero al descubrimiento del estrecho de Magallanes 1537-1538”. Anuario Hidrográfico de la marina de Chile, Año V. Santiago: Imprenta Nacional, 1879. Versión digital: http://www.memoriachilena.cl/ archivos2/pdfs/MC0012196.pdf [7-11-2016].

Darwin, Charles. Diario de un naturalista alrededor del mundo. San José de Costa Rica: ViDa Global, 2011.

Foucault, Michel. Tecnologías del yo. Y otros textos afines. Barcelona: Paidos, 1995.

Lazlo, Ervin. El universo in-formado. Una teoría integral del todo. Trad. Mercedes Domínguez Pérez. Madrid: Ediciones Nowtilus, 2007. Ebook.

Mistral, Gabriela. "Contar". Gabriela Mistral Foundation, web. http://www.gabrielamistralfoundation.org/web/index.php? Itemid=114\&id=105\&option=com_ content\&task=view [9-11-2016].

Real Academia de la Lengua, RAE. Diccionario de la Lengua Española. Edición del Tricentenario. http://dle.rae.es/?w=diccionario [29 de septiembre de 2016].

Riveros, Juan Pablo. Picton/Shukaku. Concepción: Cosmigonon Ediciones, 2014.

- - . De la Tierra sin Fuegos. Concepción: Cosmigonon Ediciones, 2001, 2da. edic.

- - . Poema del cosmos. Concepción: Cosmigonon Ediciones, 2011. 
